\title{
Neuroendoscopy for spinal disorders: a brief review
}

\author{
Eli M. Baron, M.D., Howard B. Levene, M.D., Ph.D., Joshua E. Heller, M.D., \\ Jack I. Jallo, M.D., Ph.D., Christopher M. LofTus, M.D., \\ AND Devanand A. DominiQue, M.D.
}

Department of Neurosurgery, Temple University Hospital, Philadelphia, Pennsylvania

\begin{abstract}
Neuroendoscopy has grown rapidly in the last 20 years as a therapeutic modality for treating a variety of spinal disorders. Spinal endoscopy has been widely used to treat patients with cervical, thoracic, and lumbosacral disorders safely and effectively. Although it is most commonly used with minimally invasive lumbar spine surgery, endoscopy has gained widespread acceptance for the treatment of thoracic disc herniations and for anterior release and rod implantation in the correction of thoracic spinal deformity. The authors review the use of endoscopy in spine surgery and in the treatment of spinal disorders as well as in the treatment of intrathoracic nonspinal lesions. Endoscopy has some significant advantages over open or other minimally invasive techniques in that it can allow for better visualization of the lesion, smaller incision sizes with reduced morbidity and mortality, reduced hospital stays, and ultimately lower cost. In addition, spinal endoscopy allows observers and operating room staff to be more involved in each case and fosters education. Spinal endoscopy, like any novel modality, carries with it additional risks and the surgeon must always be prepared to convert to an open procedure. The learning curve for spinal endoscopy is steep and the procedure should not be attempted alone by a novice surgeon. Nevertheless, with training and experience, the spine surgeon can achieve better outcomes, reduced morbidity, and better cosmesis with spinal endoscopy, and the operating times are comparable to open procedures. As technology evolves and more experience is obtained, neuroendoscopy will likely achieve further roles as a mainstay in spine surgery.
\end{abstract}

KeY WORDS • endoscopy • spinal disorder • lumbosacral spine

\section{BACKGROUND}

Neuroendoscopy has grown rapidly in the last 20 years as a therapeutic modality for treatment of a variety of spinal disorders. After Dubois, et al. ${ }^{20}$ reported their initial laparoscopic cholecystectomy in 1990, endoscopy grew rapidly as a familiar technology in most operating rooms. Obenchain $^{69}$ reported the first laparoscopically performed lumbar discectomy. Since then, endoscopy has been widely used for numerous disorders of the cervical, thoracic, and lumbosacral spine. Although most commonly used in minimally invasive lumbar spine surgery, ${ }^{19,23,31,37,41,58,85,92,96}$ endoscopy has gained widespread use for the treatment of thoracic disc herniations ${ }^{5,12,17,18,22,27,30,34,36,48,49,60,68,72,74,76-78,81}$ and for anterior release and rod placement in the correction of thoracic spinal deformity. $4,6,21,50,55,60,66-68,70,88,90$ We review the use of endoscopy in spine surgery and in the treatment of spinal disorders.

\section{Lumbosacral Spine}

In 1997, the field of minimally invasive spine surgery was revolutionized by the introduction of the MED retractor system, ${ }^{89}$ followed shortly by its successor, METRx (Medtronic Sofamor Danek, Minneapolis, MN). The sys- tem allowed for access to the lumbar spine by splitting of muscle fascicles with a series of dilators, allowing for a minimally invasive muscle splitting approach with minimal subsequent muscle dysfunction and pain. The use of such a tubular retractor allows the surgeon the choice of using loupes, the operating microscope, or endoscopy. ${ }^{92}$ Subsequently, excellent results have been reported for minimally invasive endoscopic lumbar discectomy and/or foraminotomy by using variants of this approach and similar retractor systems. ${ }^{13,14,35,37,61,62}$ Additionally, decompressive surgery for lumbar stenosis has been performed using this approach. ${ }^{26,46,73}$ Sairyo, et al. ${ }^{83}$ described a way to use similar techniques to perform endoscopically a modified Gill decompression of nerve roots in patients with spondylolysis. Although the procedure is less popular, good results have also been described for arthroscopic techniques for endoscopic discectomy. ${ }^{44,58}$

Anterior lumbar spinal fusion is also now becoming more commonly performed using laparoscopy. ${ }^{57,59,79,97}$ In a trial involving eight spine centers, 240 patients undergoing laparoscopic spinal fusion were compared with 591 patients undergoing fusion with the same device. ${ }^{79}$ The laparoscopic group had shorter hospital stays and decreased blood loss but also had increased operating time. Surgical complications were similar in both groups, with an occur- 
rence of $4.2 \%$ in the open approach and $4.9 \%$ in the laparoscopic approach. The authors concluded that laparoscopic fusion is associated with a higher learning curve, but with experience it is a safe and effective approach when compared with traditional surgery. Others have also reported good results. ${ }^{29,53}$ Nevertheless, the enthusiasm for laparoscopic lumbar spinal fusion is not universally shared. Numerous series have detailed minimal benefit for this approach compared with others such as the open minilaparotomy, despite the increased operating times and increased technical difficulty. ${ }^{15,43,54}$ Additionally, poor results with multilevel fusions have been described by some. ${ }^{45}$ The variability in vascular anatomy at the L4-5 segment may also make the procedure more difficult at this level. ${ }^{47}$

Several other endoscopic lumbar spinal fusion approaches have been described, including the retroperitoneal approach, ${ }^{10}$ balloon-assisted endoscopic retroperitoneal gasless approach, ${ }^{94}$ the lateral transpsoas approach, ${ }^{9}$ and percutaneous endoscopic endplate preparation with percutaneous pedicle screw insertion. ${ }^{51,52}$ The feasibility of performing lumbar endoscopic posterolateral fusion by using recombinant growth factors and an osteoconductive matrix has recently been demonstrated in a sheep model ${ }^{38} \mathrm{Ad}-$ ditionally, the feasibility of inserting endoscopic lumbar pedicle screws has been demonstrated.$^{39}$

Endoscopy has been used successfully for the treatment of lumbar spinal fractures. Olinger, et al..$^{71}$ described an endoscopic retroperitoneal approach for the treatment of fractures from the T12-L5 segments, in which disc and bone fragments were removed endoscopically, followed by bone grafting and plate placement. Schultheiss and colleagues $^{86,87}$ demonstrated good outcomes in the ventral treatment of thoracolumbar spinal fractures with endoscopically placed instrumentation. More recently, Beisse, et al., ${ }^{8}$ described good results when using anterior endoscopy in the thoracolumbar spine for decompression of the spinal canal and interbody fusion/spinal fixation for disorders arising from a variety of causes, including fractures, degenerative disc disease, tumor, and infection.

Endoscopy has also been used to treat anterior sacral meningoceles. ${ }^{75,91}$ Both laparoscopy and endoscopy may be used to place a suture around the communication between the thecal sac and cyst. Additionally, endoscopic obliteration of the connection between meningocele and spinal subarachnoid space by entering the meningocele and placing numerous fat grafts intradurally has been described..$^{40}$

Lumbar spinal canal epidural endoscopy (myeloscopy) has been used by anesthesiologists and other pain management physicians for the amelioration of lumbago, radiculopathy, and other pain syndromes. Richardson, et al. ${ }^{80}$ described using a spinal endoscope introduced through the sacral canal to target nerve roots with application of local anesthetic and steroid agents. Additionally, adhesions in contact with affected roots were mobilized. In their series of 38 patients who underwent this procedure, in which 50\% had received a diagnosis of failed-back surgery syndrome, significant improvements were seen in pain severity scores and functional abilities at 1 year. Myeloscopy potentially provides the pain specialist with another diagnostic and therapeutic tool beyond conventional imaging and surgical techniques with regard to treatment of arachnoiditis and similar conditions. ${ }^{56,93}$

\section{Thoracic Spine}

Diseases of the anterior thoracic spine require creative approaches for the spine surgeon. Prior to the $1980 \mathrm{~s},{ }^{82}$ endoscopic anterior approaches were not available and open thoracotomy was the routine. By the 1990s, however, improved endoscopic technology (for example, improved optics and video technology) had become widely available and was refined within the fields of general, urological, and thoracic surgery. It was only a matter of time before spine surgeons adopted and refined endoscopic techniques for their own use.

Endoscopic approaches have been described and are commonly used for numerous thoracic spine disorders. ${ }^{2,3}$, $7,8,16,17,25,27,32,63,64,66,67,81,82$ These include but are not limited to kyphosis surgery (that is, anterior release for deformity), scoliosis surgery, thoracic corpectomy (for trauma, tumor, degenerative change/stenosis, instability, or infection), discectomy, or biopsy sampling. Video-assisted thoracoscopic surgery has also revolutionized other procedures commonly performed within the thoracic cavity by neurosurgeons, such as sympathectomies for hyperhidrosis and shunting of cerebrospinal fluid for hydrocephalus, and has made approaches for extraaxial tumors (for example, schwannomas) safer. ${ }^{16,27}$

There are many advantages to using an endoscopic anterior approach to the thoracic spine. Thoracic ports are much smaller and are better tolerated than open thoracotomy incisions. They allow the surgeon to avoid rib resection, with consequently less potential for disruption of the underlying neurovascular bundle. Small portals also avoid excessive muscle injury, further reducing patient morbidity. This not only reduces perioperative pain but also leads to fewer pulmonary complications. The smaller wound $(4-\mathrm{cm}$ incision compared with a $20-\mathrm{cm}$ one in the traditional open approach $)^{3}$ allows for much faster recovery times and thus fewer days in the intensive care unit, shorter hospital stays, and therefore reduced cost. $3,7,8,27,81,82$

The use of thoracic endoscopy provides many additional benefits to the surgical team and operating room staff. The video documentation of a procedure can easily be shared with other medical professionals and students, allowing review and study of the steps involved in complex spine surgery cases. Inevitably, robotic assistance during video-assisted thoracoscopic spine surgery will allow the field of remote surgery to grow. The ability to have a highly skilled spine surgeon assist in operations would be quite valuable.

Just as in any novel surgical procedure, thoracoscopic spine surgery creates additional risks. The ability to visualize the working field broadly is limited by the view of the endoscope, and it is possible to damage the critical structures that lie close by. The surgeon must always be prepared to convert rapidly to an open thoracotomy, should the need arise. Just as with any anterior approach to the spine, one must be prepared to deal with pulmonary complications such as pneumothorax, hemothorax, chylothorax, and chest tube-related complications as well as potentially catastrophic conditions caused by damage to the nearby pericardia and great vessels. For procedures requiring image-guided navigation, there may be an increased risk of exposure to radiation for patients and all operating room personnel. ${ }^{7}$

Thoracoscopic approaches to the spine require that the 
surgeon receive additional training, and initially the help of a good cardiothoracic surgeon. The learning curve in thoracic spinal endoscopy can be steep. Over the last few decades there have been numerous reports from surgeons of their experiences with spinal endoscopic surgery. Adulkasem and Surangsrirat ${ }^{3}$ reported their experience with nine patients undergoing anterior spine surgery for Pott disease, vertebral compression, instability, fracture, infection, and metastatic disease. The duration of surgery ranged from 1.5 to 3 hours, with blood loss ranging from 100 to $700 \mathrm{ml}$. Of the nine patients described, seven were ambulatory by 2 to 3 days postoperatively. Several complications arose, including an adjacent segmental vertebral vessel injury in one patient, and neurapraxia as a result of traction or electrocautery injury in another.

In their landmark paper on thoracoscopic spine surgery, Newton, et al. ${ }^{65}$ reported a series of 38 patients in whom endoscopic thoracic spine surgery was performed to correct idiopathic scoliosis. Approximately 5.5 hours were required to fuse an average of seven levels. The incision length was approximately $10.5 \mathrm{~cm}$, which was estimated to be one third the length of an incision required for an open procedure. These patients were compared with 68 individuals in whom an open procedure had been performed. The scoliosis correction achieved was found to be comparable in both groups. The morbidity, however, was found to be considerably reduced by endoscopic techniques. In addition, the cosmetic result afforded by endoscopy is much more appealing to the patient. Although the surgery lasted longer when the thoracoscopic approach was used, it was assumed that as surgeons become more comfortable with endoscopy and progress along the learning curve, operating times may become comparable.

Han, et al. ${ }^{27}$ reported their experience with 241 thoracoscopic procedures, including 164 thoracic sympathectomies, 60 discectomies, five neurogenic tumor resections, eight corpectomies and spinal reconstructions, two anterior releases, and two biopsy sampling procedures. Of the patients undergoing thoracic discectomies, 98\% demonstrated complete decompression on follow-up imaging. Although sympathectomies and resection of paraspinal neurogenic tumors do not directly involve bone, the benefits afforded by this minimally invasive technique are comparable. Han's group concluded that the thoracoscopic approaches to these cases compared favorably with the alternative open approaches. Endoscopy provides better visualization of the ventral spine and spinal cord, lower morbidity rates, increased patient comfort, and superior cosmesis. In their series, open procedures could be performed faster with less blood loss; however, this again may be because of the steep learning curve associated with video-assisted thoracoscopic spine surgery. Currently, open procedures remain the operation of choice for en bloc resection of malignant tumors because of the possibility of seeding cancer cells through the less invasive technique. Perhaps in the future a combined approach, such as minithoracotomies with thoracic endoscopy, can reduce the risks associated with removing tumors in a piecemeal fashion. The personal experience of the surgeon strongly influences the choice of approach.

Image guidance for spine surgery is a relatively new technology designed to make the operation safer. Assaker ${ }^{7}$ reported on two patients for whom endoscopic spine sur- gery was supplemented by image guidance. The first patient presented with a T8-9 calcified disc and myelopathy, and the second one presented with lumbosacral disease. Although both patients did well postoperatively, the significant amount of time needed for positioning and preparation detracted greatly from the potential benefits of the technique. The authors postulate that in a specialized operating suite equipped with mobile computerized tomography or magnetic resonance imaging capabilities the preparatory time could be significantly reduced.

Endoscopic approaches to the anterior thoracic spine have also been described. Beisse, et al., ${ }^{8}$ reviewed a series consisting of 30 patients who underwent endoscopic anterior spinal canal decompression and fusion. The majority of these procedures were for thoracolumbar fractures (27 cases). The spinal canal fracture clearance was significantly increased on postoperative computerized tomography scans obtained for evaluation in the patients treated using the endoscopic technique. Ninety percent of the patients in their study improved neurologically.

Thoracoscopy can also be used safely in surgery involving the upper thoracic spine. Huang, et al., ${ }^{32}$ reported on eight patients undergoing video-assisted approaches to the upper thoracic spine (T1-4). They reported a mean surgical time of 3.1 hours, which is similar to their experience with traditional open approaches. Their patients' diseases included metastases and infectious spondylitis.

The most extensively studied as well as the most common procedure performed using video-assisted thoracic spine surgery is thoracic discectomy. In their key article, Rosenthal and Dickman ${ }^{81}$ report on their experience with herniated thoracic discs. Fifty-five patients underwent thoracoscopy, for which the mean surgical time was 3 hours and 25 minutes, and the mean blood loss was $327 \mathrm{ml}$. The approach was compared with costotransversectomy and was found to provide better resection of midline thoracic discs. Thoracoscopy afforded better visualization of the anterior dura mater, thus allowing the authors to proceed both quickly and safely. Clinical outcomes were reported as excellent, with 22 of 36 patients with myelopathy attaining complete recoveries. None of the patients in the series had worsening radicular pain or any further neurological decline.

Huntington, et al. ${ }^{34}$ used an ovine model to address the question of the ability of thoracoscopic discectomy compared with open thoracic discectomy to decompress the disc space adequately. They used 60 sheep in their study, in which the animals were killed and dissected after surgical intervention. Photographs of the vertebral end plates and remaining discs were analyzed using computer imaging. The results revealed no significant difference in the amount of disc resected, further supporting the use of an endoscopic technique.

Perez-Cruet, et al. ${ }^{74}$ described a minimally invasive posterior approach to thoracic microendoscopic discectomy. They studied seven patients with nine disc herniations. Using fluoroscopy and a visualization tube, the minimally invasive thoracic microendoscope can be placed over the facet complex of interest. Muscle dissection is minimized and visualization is aided by fiberoptic light sources. Five of seven patients had excellent results, one had good, and the other had fair results when measured on the Prolo scale.

Endoscopy has also been used in the thoracic spine to treat intradural disorders. Guest, et al., ${ }^{25}$ described a tech- 
nique in which endoscopic thoracic guidance was used to place the distal end of a shunt in the pleural space. The presenting diseases included five patients with syringomyelia, one with a perineurial cyst, and one with an arachnoid cyst. All seven patients underwent successful catheter placement. Although the surgery does not directly involve the osseous spine, the endoscopic technique is directly applicable to thoracoscopic spine surgery.

Huang, et al. ${ }^{33}$ reported specifically on complications in thoracoscopic spine surgery. Their paper is notable and commendable for bringing to light the complications of this relatively new technique. They reported on 90 consecutive patients with multiple disorders. These included 41 spinal metastases, 13 cases of scoliosis, 12 burst fractures, 10 cases of Pott disease, eight cases of pyogenic spondylitis, two thoracic disc herniations, two cases of ankylosing spondylitis with discitis, one osteoporotic compression fracture, and one case of thoracolumbar kyphosis. Thirty complications in 22 patients were noted (24.4\%). Two deaths were recorded (hemorrhage, postoperative pneumonia). Other complications included intercostal neuralgia, wound infections, pharyngeal pain, atelectasis, pneumothorax, subcutaneous emphysema, pericardial penetration, screw malposition, and graft dislodgment. Four patients required conversion to open procedures.

\section{Cervical Spine}

Endoscopy has been less widely used in the cervical than in the thoracic or lumbosacral spine, perhaps because of the relatively easy access to spinal anatomy in this region, given the relative ease of the anterior cervical approach and the smaller dissection of the posterior approach when compared with thoracolumbar anatomy. Nevertheless, an endoscopic approach may facilitate a quicker recovery with less muscle spasm, and it may promote minimal tissue disruption. Thus, endoscopic techniques, which are most commonly used for cervical disc herniations and spondylosis causing cervical radiculopathy, have been developed.

Posterior cervical endoscopic laminoforaminotomy has been advocated as an alternative to microscopic posterior laminoforaminotomy. ${ }^{1,11}$ This technique uses a modification of the microendoscopic discectomy instrumentation introduced by Smith and Foley ${ }^{89}$ Postoperatively, this may result in a marked reduction of pain and a quicker return to preoperative levels of activity. Additionally, Adamson ${ }^{2}$ reported good to excellent results in 97 of 100 patients undergoing the procedure for unilateral cervical radiculopathy. Posterior endoscopic partial cervical laminectomy was recently described by Yabuki and Kikuchi ${ }^{95}$ as a novel technique for the treatment of cervical spondylotic myelopathy. The decompression is performed one side at a time, through two $20-\mathrm{mm}$ incisions. Patients rated their postoperative neck pain as slight, and at a mean of 14.9 months their Japanese Orthopaedic Association scores had improved significantly, with no evidence of spinal instability.

Anterior endoscopic cervical foraminotomy for cervical radiculopathy has also been described. ${ }^{84}$ Saringer, et al. ${ }^{84}$ used the microendoscopic discectomy system in conjunction with a modification of Jho's ${ }^{42}$ technique of resection of the uncovertebral joint to allow for anterior endoscopic cervical nerve root decompression. Advantages of this technique include a very small surgical exposure, improved in- traoperative visualization, direct decompression and visualization of the nerve root, and avoidance of graft-related complications/preservation of the motion segment (a bone graft is not required).

Endoscopy may also be useful for diseases involving the odontoid process. Hashizume, et al., ${ }^{28}$ described using endoscopic assistance for the placement of odontoid screws in Type II odontoid fractures. An endoscopic tube was custom made for the approach based on the preoperative $\mathrm{x}$-ray films. The tube, cut obliquely at $40^{\circ}$, was used as a retractor and the endoscope was used to visualize screw insertion. Frempong-Boadu, et al., ${ }^{24}$ described an endoscopic technique to assist a transoral-transpharyngeal approach to the craniovertebral junction and to facilitate subsequent decompression. Seven patients with upper cervical and clival abnormalities were treated. The pathological entities encountered included basilar invagination, craniovertebral junction malformations, migration of odontoid fracture, pseudogout granulation mass, and a clivus chordoma. All seven patients attained adequate decompression with improved or stable neurological outcomes. One patient died of a perioperative myocardial infarction. When used with intraoperative fluoroscopy, the endoscopic approach allows broader visualization as well as minimization of soft-palate splitting.

\section{CONCLUSIONS}

Use of neuroendoscopy has become widespread in spine surgery for indications ranging from degenerative disease to deformity correction. Although at present it is most widely used in minimally invasive spine and thoracoscopic surgery, novel uses continue to emerge in the literature. As technology evolves and more experience is obtained, neuroendoscopy will likely achieve additional roles as a mainstay in spine surgery.

\section{References}

1. Adamson TE: The impact of minimally invasive cervical spine surgery. Invited submission from the Joint Section Meeting on Disorders of the Spine and Peripheral Nerves, March 2004. J Neurosurg Spine 1:43-46, 2004

2. Adamson TE: Microendoscopic posterior cervical laminoforaminotomy for unilateral radiculopathy: results of a new technique in 100 cases. J Neurosurg 95 (1 Suppl):51-57, 2001

3. Adulkasem W, Surangsrirat W: Early experience of endoscopyassisted anterior spinal surgery. J Orthop Surg (Hong Kong) 10:152-159, 2002

4. Al-Sayyad MJ, Crawford AH, Wolf RK: Video-assisted thoracoscopic surgery: the Cincinnati experience. Clin Orthop Relat Res 434:61-70, 2005

5. Anand N, Regan JJ: Video-assisted thoracoscopic surgery for thoracic disc disease: classification and outcome study of 100 consecutive cases with a 2 -year minimum follow-up period. Spine 27:871-879, 2002

6. Arlet V: Anterior thoracoscopic spine release in deformity surgery: a meta-analysis and review. Eur Spine J 9 (Suppl 1):S17-S23, 2000

7. Assaker R: Minimal access spinal technologies: state-of-the-art, indications, and techniques. Joint Bone Spine 71:459-469, 2004

8. Beisse R, Muckley T, Schmidt MH, et al: Surgical technique and results of endoscopic anterior spinal canal decompression. J Neurosurg Spine 2:128-136, 2005 
9. Bergey DL, Villavicencio AT, Goldstein T, et al: Endoscopic lateral transpsoas approach to the lumbar spine. Spine 29: 1681-1688, 2004

10. Boos N, Kalberer F, Schoeb O: Retroperitoneal endoscopically assisted minilaparotomy for anterior lumbar interbody fusion: technical feasibility and complications. Spine 26:E1-E6, 2001

11. Burke TG, Caputy A: Microendoscopic posterior cervical foraminotomy: a cadaveric model and clinical application for cervical radiculopathy. J Neurosurg 93 (1 Suppl):126-129, 2000

12. Caputy A, Starr J, Riedel C: Video-assisted endoscopic spinal surgery: thoracoscopic discectomy. Acta Neurochir (Wien) 134:196-199, 1995

13. Cervellini P, De Luca GP, Mazzetto M, et al: Micro-endoscopic-discectomy (MED) for far lateral disc herniation in the lumbar spine. Technical note. Acta Neurochir Suppl 92:99-101, 2005

14. Chiu JC: Evolving transforaminal endoscopic microdecompression for herniated lumbar discs and spinal stenosis. Surg Technol Int 13:276-286, 2004

15. Chung SK, Lee SH, Lim SR, et al: Comparative study of laparoscopic L5-s1 fusion versus open mini-ALIF, with a minimum 2-year follow-up. Eur Spine J 12:613-617, 2003

16. Dickman CA, Apfelbaum RI: Thoracoscopic microsurgical excision of a thoracic schwannoma. Case report. J Neurosurg 88: 898-902, 1998

17. Dickman CA, Mican CA: Multilevel anterior thoracic discectomies and anterior interbody fusion using a microsurgical thoracoscopic approach. Case report. J Neurosurg 84:104-109, 1996

18. Dickman CA, Rosenthal D, Regan JJ: Reoperation for herniated thoracic discs. J Neurosurg 91 (2 Suppl):157-162, 1999

19. Ditsworth DA: Endoscopic transforaminal lumbar discectomy and reconfiguration: a postero-lateral approach into the spinal canal. Surg Neurol 49:588-598, 1998

20. Dubois F, Icard P, Berthelot G, et al: Coelioscopic cholecystectomy. Preliminary report of 36 cases. Ann Surg 211:60-62, 1990

21. Early SD, Newton PO, White KK, et al: The feasibility of anterior thoracoscopic spine surgery in children under 30 kilograms. Spine 27:2368-2373, 2002

22. Fessler RG, Sturgill M: Review: complications of surgery for thoracic disc disease. Surg Neurol 49:609-618, 1998

23. Frank E: Endoscopically assisted open removal of laterally herniated lumbar discs. Surg Neurol 48:430-434, 1997

24. Frempong-Boadu AK, Faunce WA, Fessler RG: Endoscopically assisted transoral-transpharyngeal approach to the craniovertebral junction. Neurosurgery 51 (5 Suppl):S60-S66, 2002

25. Guest JD, Silbert L, Casas CE: Use of percutaneous endoscopy to place syringopleural or cystoperitoneal cerebrospinal fluid shunts. Technical note. J Neurosurg Spine 2:498-504, 2005

26. Guiot BH, Khoo LT, Fessler RG: A minimally invasive technique for decompression of the lumbar spine. Spine 27: 432-438, 2002

27. Han PP, Kenny K, Dickman CA: Thoracoscopic approaches to the thoracic spine: experience with 241 surgical procedures. Neurosurgery 51 (5 Suppl):S88-S95, 2002

28. Hashizume H, Kawakami M, Kawai M, et al: A clinical case of endoscopically assisted anterior screw fixation for the type II odontoid fracture. Spine 28:E102-E105, 2003

29. Henry LG, Cattey RP, Stoll JE, et al: Laparoscopically assisted spinal surgery. JSLS 1:341-344, 1997

30. Horowitz MB, Moossy JJ, Julian T, et al: Thoracic discectomy using video assisted thoracoscopy. Spine 19:1082-1086, 1994

31. Hsieh PC, Wang CH: Posterior endoscopic lumbar discectomy using a thoracoport as a tubular retractor. Minim Invasive Neurosurg 47:319-323, 2004

32. Huang TJ, Hsu RW, Liu HP, et al: Video-assisted thoracoscopic surgery to the upper thoracic spine. Surg Endosc 13: 123-126, 1999

33. Huang TJ, Hsu RW, Sum CW, et al: Complications in thoraco- scopic spinal surgery: a study of 90 consecutive patients. Surg Endosc 13:346-350, 1999

34. Huntington CF, Murrell WD, Betz RR, et al: Comparison of thoracoscopic and open thoracic discectomy in a live ovine model for anterior spinal fusion. Spine 23:1699-1702, 1998

35. Husain M, Jha DK, Agrawal S, et al: Conical working tube: a special device for endoscopic surgery of herniated lumbar discs. J Neurosurg Spine 2:265-270, 2005

36. Ikard RW, McCord DH: Thoracoscopic exposure of intervertebral discs. Ann Thorac Surg 61:1267-1268, 1996

37. Isaacs RE, Podichetty V, Fessler RG: Microendoscopic discectomy for recurrent disc herniations. Neurosurg Focus 15(3): E11, 2003

38. Jahng TA, Fu TS, Cunningham BW, et al: Endoscopic instrumented posterolateral lumbar fusion with Healos and recombinant human growth/differentiation factor-5. Neurosurgery 54: 171-181, 2004

39. Jahng TA, Fu TS, Kim DH: Open versus endoscopic lumbar pedicle screw fixation and posterolateral fusion in a sheep model: a feasibility study. Spine J 4:519-526, 2004

40. Jeon BC, Kim DH, Kwon KY: Anterior endoscopic treatment of a huge anterior sacral meningocele: technical case report. Neurosurgery 52:1231-1234, 2003

41. Jho HD: Endoscopic transpedicular thoracic discectomy. J Neurosurg 91 (2 Suppl): 151-156, 1999

42. Jho HD: Microsurgical anterior cervical foraminotomy for radiculopathy: a new approach to cervical disc herniation. J Neurosurg 84:155-160, 1996

43. Kaiser MG, Haid RW Jr, Subach BR, et al: Comparison of the mini-open versus laparoscopic approach for anterior lumbar interbody fusion: a retrospective review. Neurosurgery 51: 97-105, 2002

44. Kambin P: Arthroscopic microdiskectomy. Mt Sinai J Med 58: 159-164, 1991

45. Katkhouda N, Campos GM, Mavor E, et al: Is laparoscopic approach to lumbar spine fusion worthwhile? Am J Surg 178: 458-461, 1999

46. Khoo LT, Fessler RG: Microendoscopic decompressive laminotomy for the treatment of lumbar stenosis. Neurosurgery 51 (5 Suppl):S146-S154, 2002

47. Kleeman TJ, Michael Ahn U, Clutterbuck WB, et al: Laparoscopic anterior lumbar interbody fusion at L4-L5: an anatomic evaluation and approach classification. Spine 27:1390-1395, 2002

48. Kuklo TR, Lenke LG: Thoracoscopic spine surgery: current indications and techniques. Orthop Nurs 19:15-22, 2000

49. Lee YY, Huang TJ, Liu HP, et al: Thoracic disc herniation treated by video-assisted thoracoscopic surgery: case report. Changgeng Yi Xue Za Zhi 21:453-457, 1998

50. Lenke LG, Newton PO, Marks MC, et al: Prospective pulmonary function comparison of open versus endoscopic anterior fusion combined with posterior fusion in adolescent idiopathic scoliosis. Spine 29:2055-2060, 2004

51. Leu HF, Hauser RK: Percutaneous endoscopic lumbar spine fusion. Neurosurg Clin N Am 7:107-117, 1996

52. Leu HF, Hauser RK, Schreiber A: Lumbar percutaneous endoscopic interbody fusion. Clin Orthop Relat Res 337:58-63, 1997

53. Lieberman IH, Willsher PC, Litwin DE, et al: Transperitoneal laparoscopic exposure for lumbar interbody fusion. Spine 25: 509-515, 2000

54. Liu JC, Ondra SL, Angelos P, et al: Is laparoscopic anterior lumbar interbody fusion a useful minimally invasive procedure? Neurosurgery 51 (5 Suppl):S155-S158, 2002

55. Mack MJ, Regan JJ, Bobechko WP, et al: Application of thoracoscopy for diseases of the spine. Ann Thorac Surg 56: 736-738, 1993

56. Manchikanti L, Singh V: Epidural lysis of adhesions and myeloscopy. Curr Pain Headache Rep 6:427-435, 2002 
57. Mathews HH, Evans MT, Molligan HJ, et al: Laparoscopic discectomy with anterior lumbar interbody fusion. A preliminary review. Spine 20:1797-1802, 1995

58. Mayer HM, Brock M: Percutaneous endoscopic discectomy: surgical technique and preliminary results compared to microsurgical discectomy. J Neurosurg 78:216-225, 1993

59. McAfee PC, Regan JJ, Geis WP, et al: Minimally invasive anterior retroperitoneal approach to the lumbar spine. Emphasis on the lateral BAK. Spine 23:1476-1484, 1998

60. McAfee PC, Regan JR, Zdeblick T, et al: The incidence of complications in endoscopic anterior thoracolumbar spinal reconstructive surgery. A prospective multicenter study comprising the first 100 consecutive cases. Spine 20:1624-1632, 1995

61. Muramatsu K, Hachiya Y, Morita C: Postoperative magnetic resonance imaging of lumbar disc herniation: comparison of microendoscopic discectomy and Love's method. Spine 26: 1599-1605, 2001

62. Nakagawa H, Kamimura M, Uchiyama S, et al: Microendoscopic discectomy (MED) for lumbar disc prolapse. J Clin Neurosci 10:231-235, 2003

63. Newton PO: The use of video-assisted thoracoscopic surgery in the treatment of adolescent idiopathic scoliosis. Instr Course Lect 54:551-558, 2005

64. Newton PO, Lee SS, Mahar AT, et al: Thoracoscopic multilevel anterior instrumented fusion in a goat model. Spine 28: 1614-1620, 2003

65. Newton PO, Marks M, Faro F, et al: Use of video-assisted thoracoscopic surgery to reduce perioperative morbidity in scoliosis surgery. Spine 28 (Suppl):S249-S254, 2003

66. Newton PO, Shea KG, Granlund KF: Defining the pediatric spinal thoracoscopy learning curve: sixty-five consecutive cases. Spine 25: 1028-1035, 2000

67. Newton PO, Wenger DR, Mubarak SJ, et al: Anterior release and fusion in pediatric spinal deformity. A comparison of early outcome and cost of thoracoscopic and open thoracotomy approaches. Spine 22:1398-1406, 1997

68. Nymberg SM, Crawford AH: Video-assisted thoracoscopic releases of scoliotic anterior spines. AORN J 63:561-562, 565-569; 571-565; quiz 576, pass, 1996

69. Obenchain TG: Laparoscopic lumbar discectomy: case report. J Laparoendosc Surg 1:145-149, 1991

70. Ohtsuka T, Ohnishi I, Nakamura K, et al: New instrumentation for video-assisted anterior spine release. Surg Endosc 14: 682-684, 2000

71. Olinger A, Hildebrandt U, Mutschler W, et al: First clinical experience with an endoscopic retroperitoneal approach for anterior fusion of lumbar spine fractures from levels T12 to L5. Surg Endosc 13:1215-1219, 1999

72. Osman SG, Marsolais EB: Posterolateral arthroscopic discectomies of the thoracic and lumbar spine. Clin Orthop Relat Res 304:122-129, 1994

73. Palmer S, Turner R, Palmer R: Bilateral decompression of lumbar spinal stenosis involving a unilateral approach with microscope and tubular retractor system. J Neurosurg 97 (2 Suppl): 213-217, 2002

74. Perez-Cruet MJ, Kim BS, Sandhu F, et al: Thoracic microendoscopic discectomy. J Neurosurg Spine 1:58-63, 2004

75. Raftopoulos C, Pierard GE, Retif C, et al: Endoscopic cure of a giant sacral meningocele associated with Marfan's syndrome: case report. Neurosurgery 30:765-768, 1992

76. Regan JJ: Percutaneous endoscopic thoracic discectomy. Neurosurg Clin N Am 7:87-98, 1996

77. Regan JJ, Ben-Yishay A, Mack MJ: Video-assisted thoracoscopic excision of herniated thoracic disc: description of technique and preliminary experience in the first 29 cases. J Spinal Disord 11:183-191, 1998

78. Regan JJ, Mack MJ, Picetti GD III: A technical report on video- assisted thoracoscopy in thoracic spinal surgery. Preliminary description. Spine 20:831-837, 1995

79. Regan JJ, Yuan H, McAfee PC: Laparoscopic fusion of the lumbar spine: minimally invasive spine surgery. A prospective multicenter study evaluating open and laparoscopic lumbar fusion. Spine 24:402-411, 1999

80. Richardson J, McGurgan P, Cheema S, et al: Spinal endoscopy in chronic low back pain with radiculopathy. A prospective case series. Anaesthesia 56:454-460, 2001

81. Rosenthal D, Dickman CA: Thoracoscopic microsurgical excision of herniated thoracic discs. J Neurosurg 89:224-235, 1998

82. Rosenthal D, Marquardt G, Lorenz R, et al: Anterior decompression and stabilization using a microsurgical endoscopic technique for metastatic tumors of the thoracic spine. J Neurosurg 84:565-572, 1996

83. Sairyo K, Katoh S, Sakamaki T, et al: A new endoscopic technique to decompress lumbar nerve roots affected by spondylolysis. Technical note. J Neurosurg 98 (3 Suppl):290-293, 2003

84. Saringer WF, Reddy B, Nobauer-Huhmann I, et al: Endoscopic anterior cervical foraminotomy for unilateral radiculopathy: anatomical morphometric analysis and preliminary clinical experience. J Neurosurg 98 (2 Suppl): 171-180, 2003

85. Schick U, Dohnert J: Technique of microendoscopy in medial lumbar disc herniation. Minim Invasive Neurosurg 45: 139-141, 2002

86. Schultheiss M, Hartwig E, Kinzl L, et al: Thoracolumbar fracture stabilization: comparative biomechanical evaluation of a new video-assisted implantable system. Eur Spine J 13:93-100, 2004

87. Schultheiss M, Kinzl L, Claes L, et al: Minimally invasive ventral spondylodesis for thoracolumbar fracture treatment: surgical technique and first clinical outcome. Eur Spine J 12: 618-624, 2003

88. Schwab FJ, Smith V, Farcy JP: Endoscopic thoracoplasty and anterior spinal release in scoliotic deformity. Bull Hosp Jt Dis 59:27-32, 2000

89. Smith M, Foley K: Microendoscopic discectomy. Tech Neurosurg 3:301-307, 1997

90. Sucato DJ: Thoracoscopic anterior instrumentation and fusion for idiopathic scoliosis. J Am Acad Orthop Surg 11:221-227, 2003

91. Tani S, Okuda Y, Abe T: Surgical strategy for anterior sacral meningocele. Neurol Med Chir 43:204-209, 2003

92. Thongtrangan I, Le H, Park J, et al: Minimally invasive spinal surgery: a historical perspective. Neurosurg Focus 16(1):E13, 2004

93. Uchiyama S, Hasegawa K, Homma T, et al: Ultrafine flexible spinal endoscope (myeloscope) and discovery of an unreported subarachnoid lesion. Spine 23:2358-2362, 1998

94. Vazquez RM, Gireesan GT: Balloon-assisted endoscopic retroperitoneal gasless (BERG) technique for anterior lumbar interbody fusion (ALIF). Surg Endosc 17:268-272, 2003

95. Yabuki S, Kikuchi S: Endoscopic partial laminectomy for cervical myelopathy. J Neurosurg Spine 2:170-174, 2005

96. Yeung AT, Yeung CA: Advances in endoscopic disc and spine surgery: foraminal approach. Surg Technol Int 11:255-263, 2003

97. Zucherman JF, Zdeblick TA, Bailey SA, et al: Instrumented laparoscopic spinal fusion. Preliminary results. Spine 20:2029-2035, 1995

Manuscript received October 20, 2005.

Accepted in final form December 2, 2005.

Address reprint requests to: Devanand A. Dominique, M.D., Department of Neurosurgery, Temple University Hospital, 3401 North Broad Street, 5th Floor Parkinson Pavilion, Philadelphia, Pennsylvania 19140. email: ddominiq@temple.edu. 